\title{
The effect of coronary angiography timing and use of cardiopulmonary bypass on acute kidney injury after coronary artery bypass graft surgery
}

\author{
Kyungmi Kim, MD, ${ }^{\mathrm{a}}$ Kyoung-Woon Joung, MD, ${ }^{\mathrm{a}}$ Sung-Mi Ji, MD, ${ }^{\mathrm{b}} \mathrm{Ji}-$ Yoon Kim, MD, \\ Eun-Ho Lee, $\mathrm{MD}, \mathrm{PhD},{ }^{\mathrm{a}}$ Cheol-Hyun Chung, $\mathrm{MD}, \mathrm{PhD},{ }^{\mathrm{c}}$ and In-Cheol Choi, $\mathrm{MD}, \mathrm{PhD}^{\mathrm{a}}$
}

\begin{abstract}
Objective: Acute kidney injury is a common but serious complication of coronary artery bypass grafting. We investigated whether the effect of the timing of coronary angiography on acute kidney injury after coronary artery bypass grafting is influenced by the use of cardiopulmonary bypass.

Methods: We included, retrospectively, 2371 patients who underwent coronary artery bypass grafting whether cardiopulmonary bypass was used (on-pump coronary artery bypass) or not (off-pump coronary artery bypass). Postoperative acute kidney injury was defined by the consensus Kidney Disease: Improving Global Outcomes Definition and Staging criteria. Multivariate logistic regression and propensity score analysis were performed to evaluate the association of the time interval between coronary angiography and coronary artery bypass grafting with postoperative acute kidney injury.
\end{abstract}

Results: The incidence of acute kidney injury was higher in patients who underwent coronary angiography 7 days or less before coronary artery bypass grafting than in those who underwent it more than 7 days before coronary artery bypass grafting $(42.7 \%$ vs $38.5 \%, P=.037)$. There was significant interaction between the timing of coronary angiography and the use of cardiopulmonary bypass for postoperative acute kidney injury $(P=.019)$. The time interval between coronary angiography and surgery was independently associated with postoperative acute kidney injury in patients undergoing on-pump coronary artery bypass only. In an adjusted propensity score model, coronary angiography within 7 days of on-pump coronary artery bypass was a predictor of postoperative acute kidney injury (odds ratio, 1.742; 95\% confidence interval, 1.144-2.653; $P=.010)$.

Conclusions: A shorter interval between coronary angiography and surgery influenced the occurrence of acute kidney injury in patients undergoing on-pump coronary artery bypass. However, the interval is not an independent risk factor for the development of postoperative acute kidney injury in patients who undergo off-pump coronary artery bypass. (J Thorac Cardiovasc Surg 2016;152:254-61)

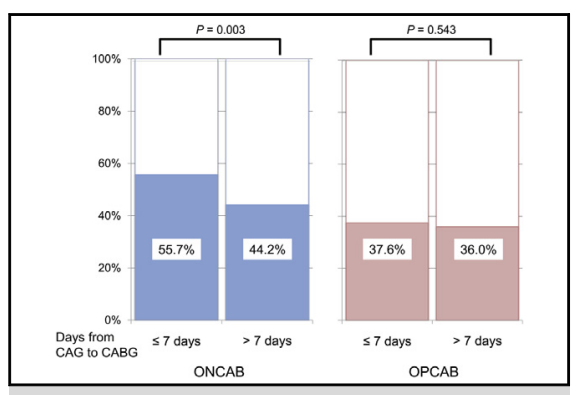

The incidence of $\mathrm{AKI}$ in each operation performed within 7 days after $C A B G$ or not.

\section{Central Message}

A shorter interval between coronary angiography and surgery affects the occurrence of $\mathrm{AKI}$ in patients undergoing $\mathrm{CABG}$ with $\mathrm{CPB}$.

\section{Perspective}

A shorter interval between coronary angiography and surgery increased the risk of postoperative $\mathrm{AKI}$ in patients undergoing $\mathrm{ONCAB}$ but did not affect the development of postoperative $\mathrm{AKI}$ in patients undergoing OPCAB. Our current evidence should be considered when you need to increase the convenience of patients, reduce the economic burden of patients, and shorten the hospital stay.

See Editorial Commentary page 262.
From the Departments of anesthesiology and Pain Medicine and ${ }^{\mathrm{c}}$ Thoracic and Cardiovascular Surgery, Asan Medical Center, University of Ulsan College of Medicine, Seoul; and ${ }^{\mathrm{b}}$ Department of Anesthesiology and Pain Medicine, College of Medicine, Dankook University, Cheonan, Korea.

Received for publication May 15, 2015; revisions received Feb 4, 2016; accepted for publication Feb 19, 2016; available ahead of print April 5, 2016.

Address for reprints: Eun-Ho Lee, MD, PhD, Department of Anesthesiology and Pain Medicine, Asan Medical Center, University of Ulsan College of Medicine, 88 Olympic-ro 43 gil, Songpa-gu, Seoul 05505, Korea (E-mail: leho@ naver.com). $0022-5223 / \$ 36.00$

Copyright (c) 2016 by The American Association for Thoracic Surgery

http://dx.doi.org/10.1016/j.jtcvs.2016.02.063
Acute kidney injury (AKI) is a serious complication of coronary artery bypass grafting (CABG) that shows an incidence of $3 \%$ to $30 \%$, depending on the definition

Scanning this QR code will take you to supplemental data and tables for this article. 


$$
\begin{aligned}
& \text { Abbreviations and Acronyms } \\
& \begin{aligned}
& \text { AKI }=\text { acute kidney injury } \\
& \text { CABG }=\text { coronary artery bypass grafting } \\
& \text { CI }=\text { confidence interval } \\
& \text { CPB }=\text { cardiopulmonary bypass } \\
& \text { ICU }=\text { intensive care unit } \\
& \text { KDIGO } \text { Kidney Disease: Improving Global } \\
& \text { Outcomes Definition and Staging } \\
& \text { ONCAB }=\text { on-pump coronary artery bypass } \\
& \text { OPCAB }=\text { off-pump coronary artery bypass } \\
& \text { OR }=\text { odds ratio } \\
& \text { RRT }=\text { renal replacement therapy } \\
& \text { sCr }=\text { serum creatinine }
\end{aligned}
\end{aligned}
$$

\section{MATERIALS AND METHODS Subjects}

This study retrospectively reviewed the electronic medical records and laboratory results of all patients who underwent CABG with or without CPB at Asan Medical Center between January 2006 and December 2012. The study protocol was approved by the Institutional Review Board of Asan Medical Center, Seoul, Korea (AMC IRB 2014-0623). During the study period, 2643 patients underwent ONCAB or OPCAB. However, 153 patients underwent emergency or urgent surgery, 97 patients were on hemodialysis, and 16 patients had undergone other valve surgery; in addition, there was no record of the interval between the coronary angiography and the operation for 6 patients. Thus, a total of 2371 patients were finally included (Figure 1).

Demographic variables examined included patient age, gender, and body mass index; history of hypertension, diabetes, smoking, or previous intervention or surgery of the coronary artery; cerebrovascular disease, hemorrhagic stroke, transient ischemic attack, or severe narrowing of the carotid arteries; peripheral artery disease, defined as stenosis of 1 or more peripheral arteries with more than $50 \%$ occlusion of the vessel lumen except the cerebral and carotid artery; and preoperative renal dysfunction, determined by an estimated glomerular filtration rate less than $60 \mathrm{~mL} / \mathrm{min} / 1.73 \mathrm{~m}^{2}$ based on preoperative creatinine clearance, calculated using the Modification of Diet in Renal Disease equation II. ${ }^{12}$ The baseline laboratory values were defined as measured values the day before surgery or immediately before surgery when coronary angiography was performed on the same day of operation. Clinical data for the 2371 patients who underwent isolated elective CABG were obtained from the CABG and anesthesia database of Asan Medical Center and from a retrospective review of the computerized patient record system. This study was performed in accordance with Strengthening the Reporting of Observational Studies in Epidemiology criteria. $^{13}$

\section{Perioperative Management}

Preoperative management, anesthetic, and surgical techniques were standardized for all patients. ${ }^{14}$ Coronary angiography, CABG, and perioperative management were performed in the standard manner, and the day of the elective surgery was chosen by the cardiac surgeons. The routine protocol for patients scheduled for angiography at Asan Medical Center has been reported. ${ }^{9}$ In our institution, CABG

AKI in some studies but not in AKI in some studies but not in others. In our previous study, however, the risk of postoperative AKI was not related to the time between coronary angiography and off-pump coronary artery bypass (OPCAB). ${ }^{9}$ Moreover, some studies have reported that neither use nor duration of $\mathrm{CPB}$ is an independent risk factor for postoperative deterioration in the glomerular filtration rate or for the occurrence of AKI. ${ }^{10,11}$

Although numerous studies have been performed in this research field, no report to date has compared the effect of the time from coronary angiography to CABG according to $\mathrm{CPB}$ use. Thus, we investigated whether the effect of the timing of coronary angiography on AKI after CABG is influenced by the use of CPB. We hypothesized that a short interval between coronary angiography and CABG would be associated with an increased risk of AKI development and that a shorter interval between coronary angiography and CABG would have a more serious impact on the occurrence of AKI in patients undergoing on-pump coronary artery bypass (ONCAB).
Emergency or Urgent surgery ( $n=153)$ Hemodialysis prior to surgery $(n=97)$ Concomitant valvular surgery $(n=16)$ Missing records $(n=6)$

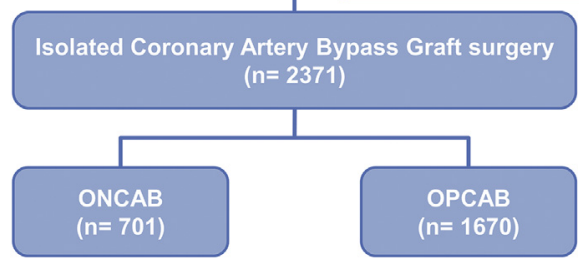

FIGURE 1. Enrollment of patients. $O N C A B$, On-pump coronary artery bypass; $O P C A B$, off-pump coronary artery bypass. 
was performed by 4 experienced cardiac surgeons, who incidentally preferred OPCAB rather than ONCAB. The decision to use $\mathrm{CPB}$ was made at the discretion of the attending cardiac surgeon. Indicated criteria of ONCAB were as follows: moderate to severe cardiomegaly; anticipation of difficult surgical approaches due to anatomic variances of coronary artery; poor-quality target vessels, including intramyocardial vessels, diffusely diseased vessels, and calcified coronary vessels; hemodynamic instability; impaired left ventricular function; and severe pulmonary disease.

\section{Definitions and End Point}

The primary end point was the impact of the timing between coronary angiography and surgery on AKI development. Postoperative AKI was defined according to Kidney Disease: Improving Global Outcomes Definition and Staging (KDIGO) criteria using the maximal change in serum creatinine ( $\mathrm{sCr}$ ) during the first 7 postoperative days compared with the preoperative baseline values. ${ }^{15}$ AKI was defined by either of the following: an increase in $\mathrm{sCr} 0.3 \mathrm{mg} / \mathrm{dL}$ or greater within 48 hours or an increase in $\mathrm{sCr}$ 1.5 times baseline or greater, which was known or presumed to have occurred within the prior 7 days. AKI also was staged for severity according to the following criteria:

Stage 1 , increase in $\mathrm{sCr} 0.3 \mathrm{mg} / \mathrm{dL}$ or greater or to 1.5 to 1.9 times the baseline.

Stage 2, increase in sCr to 2.0 to 2.9 times the baseline.

Stage 3, increase in sCr to 3.0 or more times the baseline; increase in $\mathrm{sCr}$ $4.0 \mathrm{mg} / \mathrm{dL}$ or greater or initiation of renal replacement therapy (RRT).

We assessed the association of postoperative AKI with postoperative outcomes, such as time to extubation, intensive care unit (ICU) and hospital stay, and mortality. One-year RRT or death collectively refers to cases of RRT and deaths that occurred during the first postoperative year. For the confirmation of 1-year RRT or death, our investigators examined the electronic medical records, national health insurance status, or registration of death and conducted a telephone interview with the family of the patients.

\section{Statistical Analysis}

All of the data in the study were summarized as mean \pm standard deviation or medians with interquartile range (when the distribution of values is skewed) for continuous variables or numbers and percentages for categoric variables. In univariate analysis to compare the differences between groups, categoric data were analyzed using the chi-square or Fisher exact tests. The Student $t$ test or Mann-Whitney rank-sum test was used for continuous variables.

Univariate logistic regression analysis was used to identify demographic, preoperative laboratory, and coronary angiographic factors significantly associated with AKI development (Table E1). Variables with a $P$ value less than .1 in univariate logistic regression analysis were included in the multivariable logistic regression analysis to determine independent factors for AKI. First, the effect of time interval between coronary angiography and CABG on AKI development was analyzed as a continuous variable in univariate and multivariable logistic models. We performed $\log$ transformation on this variable to account for a possible nonlinear relationship between coronary angiography timing and AKI. To assess whether the effect of the time interval between coronary angiography and $\mathrm{CABG}$ on postoperative AKI was influenced by the use of $\mathrm{CPB}$, we tested for the presence of any interaction between the timing of coronary angiography and the use of CPB. Subsequently, patients were divided into 2 groups on the basis of the use of CPB (ie, ONCAB and $\mathrm{OPCAB}$ ). We also analyzed the days between coronary angiography and CABG as categoric variables using 7 days as the cutoff. This cutoff was based on our preliminary analysis including the receiver operating characteristic curve analysis $(P=.020$, data not shown) and regression analysis and a previous report suggesting that after being exposed contrast, renal function usually returns to preexisting levels within 7 to 21 days. ${ }^{16,17}$ Also, to control for selection bias related to covariates, we performed a propensity score analysis. Without regard to outcome variables, the propensity scores for the likelihood of receiving coronary angiography 7 or less days before CABG were developed and a hierarchical logistic regression model to calculate the propensity score was applied (details are provided in Supplemental Methods). Then, an unadjusted logistic regression model was developed using a propensity score for independent predictors of the development of postoperative AKI after CABG; the obtained predictors were subsequently tested in an adjusted logistic regression model. The adjusted logistic regression model was built using variables that showed a $P$ value less than .1 in the unadjusted logistic propensity score regression model. A stepwise approach was used and confirmed by backward and forward methods. The significance within the models was evaluated with the Wald test, whereas the strength of the association of variables with AKI was estimated by calculating the odds ratios (ORs) and $95 \%$ confidence intervals (CIs). The adjusted logistic model was calibrated by the Hosmer-Lemeshow goodness-of-fit test, as well as residual diagnostics (deviance and dfBetas); model discrimination was evaluated by using the area under the receiver operating characteristic curve. The process was repeated to confirm the impact of the timing between coronary angiography and surgery on AKI development in each operation group. All tests were 2-sided with the alpha level set at 0.05 for statistical significance. All statistical analyses were performed using SPSS 21.0 (SPSS Inc, Chicago, Ill) and SAS 9.3 (SAS Institute Inc, Cary, NC).

\section{RESULTS}

The demographic characteristics, preoperative laboratory findings, and intraoperative variables of the 2371 included patients are shown in Table 1. In total, 964 patients $(40.7 \%)$ had postoperative AKI. The incidence of AKI differed between the types of surgery: $49.8 \%$ in patients who underwent $\mathrm{ONCAB}$ and $36.8 \%$ in patients who underwent OPCAB $(P<.001)$. Moreover, the incidence of AKI was significantly higher in patients who underwent coronary angiography $\leq 7$ days before ONCAB than in those of $>7$ days $(55.7 \%$ vs $44.2 \%, P=.003$; Figure 2). There were no significant differences in preoperative renal function, preoperative laboratory levels including $\mathrm{sCr}$, and elapsed time interval from coronary angiography to operation between patients who underwent $\mathrm{ONCAB}$ and patients who underwent $\mathrm{OPCAB}$ (Table 1).

Postoperative morbidity and mortality are shown in Table 2. Patients affected by postoperative AKI experienced a longer time to extubation, ICU stay, and hospital stay. Moreover, the rates of in-hospital death and 1-year mortality were significantly higher in patients who experienced postoperative AKI than in those without this complication $(P<.001$ and $P=.011$, respectively). There were higher occurrences of RRT and more deaths during the first postoperative year in patients affected by postoperative AKI than in those without AKI $(P<.001)$. The reoperation rate, the Cardiovascular Sequential Organ Failure Assessment score during the first 24 hours of ICU stay, and the weight change were higher in the patients affected by AKI than in those not 
TABLE 1. Baseline and operative characteristics of study patients stratified by type of surgery

\begin{tabular}{|c|c|c|c|}
\hline & $\begin{array}{c}\text { ONCAB } \\
(\mathbf{n}=701)\end{array}$ & $\begin{array}{c}\text { OPCAB } \\
(\mathbf{n}=1670)\end{array}$ & $\begin{array}{c}P \\
\text { value }\end{array}$ \\
\hline Age (y) & $63.5 \pm 9.0$ & $63.7 \pm 9.3$ & .643 \\
\hline Male & $514(73.3 \%)$ & $1286(77.0 \%)$ & .056 \\
\hline Body mass index $\left(\mathrm{kg} / \mathrm{m}^{2}\right)$ & $24.7 \pm 3.0$ & $24.6 \pm 2.9$ & .911 \\
\hline Hypertension & $416(59.3 \%)$ & $1071(64.1 \%)$ & .029 \\
\hline Diabetes mellitus & $322(45.9 \%)$ & $776(46.5 \%)$ & .822 \\
\hline Smoking & & & $<.001$ \\
\hline No & $340(48.5 \%)$ & $750(44.9 \%)$ & \\
\hline Ex-smoker & $231(33.0 \%)$ & $473(28.3 \%)$ & \\
\hline Current & $130(18.5 \%)$ & $447(26.8 \%)$ & \\
\hline Congestive heart failure & $33(4.7 \%)$ & $43(2.6 \%)$ & .008 \\
\hline Cerebrovascular disease & $236(33.7 \%)$ & $350(21.0 \%)$ & $<.001$ \\
\hline Peripheral vascular disease & $26(3.7 \%)$ & $98(5.9 \%)$ & .033 \\
\hline $\mathrm{eGFR}<60 \mathrm{~mL} / \mathrm{min} / 1.73 \mathrm{~m}^{2}$ & $125(17.8 \%)$ & $279(16.7 \%)$ & .511 \\
\hline Liver disease & $18(2.6 \%)$ & $46(2.8 \%)$ & .890 \\
\hline \multicolumn{4}{|l|}{ Preoperative medication } \\
\hline $\mathrm{ACEi}$ & $315(44.9 \%)$ & $692(41.4 \%)$ & .112 \\
\hline Beta-blocker & $401(57.2 \%)$ & $1073(64.3 \%)$ & .001 \\
\hline Calcium channel blocker & $446(63.6 \%)$ & $1206(72.2 \%)$ & $<.001$ \\
\hline Insulin & $61(8.7 \%)$ & $459(27.5 \%)$ & $<.001$ \\
\hline Oral hypoglycemic agents & $271(38.7 \%)$ & $598(35.8 \%)$ & 191 \\
\hline Statin & $469(66.9 \%)$ & $1188(71.1 \%)$ & .044 \\
\hline Aspirin & $578(82.5 \%)$ & $1197(71.7 \%)$ & $<.001$ \\
\hline Clopidogrel & $452(64.5 \%)$ & $870(52.1 \%)$ & $<.001$ \\
\hline Diuretics & $161(23.0 \%)$ & $290(17.4 \%)$ & .002 \\
\hline Logistic euroSCORE & $6.0 \pm 6.9$ & $3.2 \pm 3.5$ & $<.001$ \\
\hline \multicolumn{4}{|l|}{ Preoperative laboratory values } \\
\hline Hematocrit $(\%)$ & $38.2 \pm 4.9$ & $38.6 \pm 4.9$ & .117 \\
\hline Creatinine (mg/dL) & $1.0 \pm 0.3$ & $1.0 \pm 0.5$ & .719 \\
\hline Total bilirubin (mg/dL) & $0.7 \pm 0.3$ & $0.7 \pm 0.3$ & .748 \\
\hline Albumin (g/dL) & $3.7 \pm 0.5$ & $3.8 \pm 0.4$ & $<.001$ \\
\hline Uric acid (mg/dL) & $5.5 \pm 1.5$ & $5.6 \pm 1.5$ & .461 \\
\hline Ejection fraction $(\%)$ & $53.7 \pm 13.0$ & $56.7 \pm 10.2$ & $<.001$ \\
\hline Days from CAG to CABG & $8(5-15)$ & $7(4-15)$ & .647 \\
\hline$\leq 7 \mathrm{~d}$ & $341(48.6 \%)$ & $857(51.3 \%)$ & .242 \\
\hline Grafts per patients, $n$ & $3(2-3)$ & $3(2-4)$ & .036 \\
\hline Anesthetic time (min) & $312.0 \pm 77.4$ & $306.5 \pm 67.0$ & .152 \\
\hline Crystalloid $(\mathrm{mL})^{*}$ & $1093.5 \pm 548.4$ & $1622.9 \pm 731.0$ & $<.001$ \\
\hline Colloid (mL)* & $724.0 \pm 347.2$ & $1166.6 \pm 388.4$ & $<.001$ \\
\hline Packed red blood cell* ${ }^{*}$ & $460(65.6 \%)$ & $857(51.3 \%)$ & $<.001$ \\
\hline Fresh frozen plasma* & $91(13.0 \%)$ & $76(4.6 \%)$ & $<.001$ \\
\hline Cell salvage blood* & $0(0-0)$ & $0(0-240)$ & $<.001$ \\
\hline AKI & $349(49.8 \%)$ & $615(36.8 \%)$ & $<.001$ \\
\hline
\end{tabular}

Data are expressed as the mean \pm standard deviation, median (25th, 75th percentiles), or number (percentage). ONCAB, On-pump coronary artery bypass; OPCAB, off-pump coronary artery bypass; $e G F R$, estimated glomerular filtration rate; $A C E i$, angiotensin-converting enzyme inhibitor; euroSCORE, European System for Cardiac Operative Risk Evaluation; $C A G$, coronary angiography; $C A B G$, coronary artery bypass grafting; $A K I$, acute kidney injury. *Used during operation.

affected (Table E2). Most $(75 \%)$ of the patients who were affected by AKI had mild AKI (KDIGO stage 1). Although mortality rates were similar, extubation time and duration of stay in the ICU and the hospital were

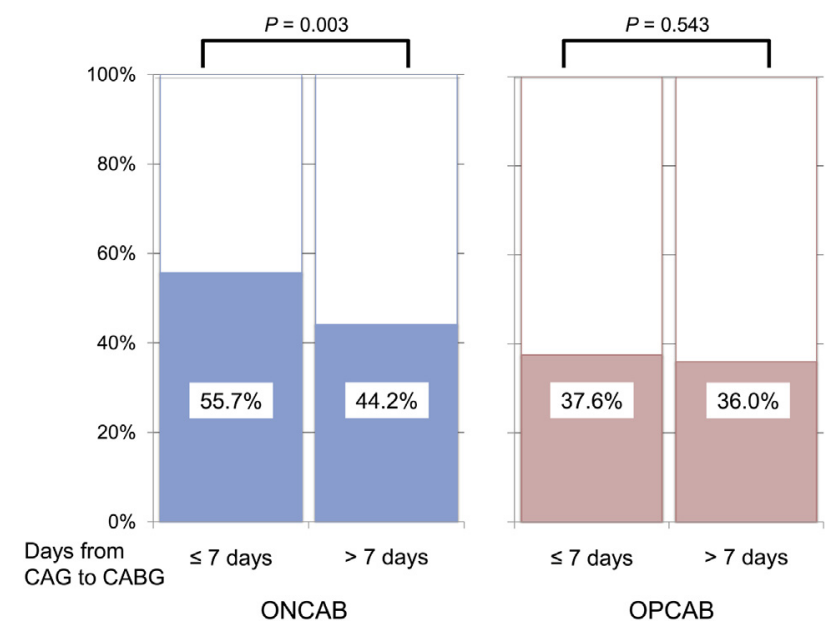

FIGURE 2. The incidence of AKI in each operation performed within 7 days after $\mathrm{CABG}$ or not. The incidence of AKI was significantly higher in patients who underwent coronary angiography $\leq 7$ days before ONCAB than in those of $>7$ days $(55.7 \%$ vs $44.2 \% ; P=.003)$. However, there was no significant difference in development of AKI between in patients who underwent $\mathrm{OPCAB}$ within 7 days after coronary angiography and in those $>7$ days after coronary angiography $(P=.543) . A K I$, Acute kidney injury; $C A B G$, coronary artery bypass graft surgery; $C A G$, coronary angiography; $O N C A B$, on-pump coronary artery bypass graft surgery; $O P C A B$, off-pump coronary artery bypass graft surgery.

significantly longer in patients with mild AKI than without AKI (Table E3).

In unadjusted univariate analysis, a shorter time interval between coronary angiogram and CABG was significantly associated with an increased risk of postoperative AKI (OR, 0.921; 95\% CI, 0.858-0.989; $P=.023$ in log-transformed continuous variables and OR, 1.191;

TABLE 2. Mortality and morbidity in the study cohort with reference to acute kidney injury development

\begin{tabular}{lccr}
\hline & No AKI $(\mathbf{n}=\mathbf{1 4 0 7})$ & AKI $(\mathbf{n}=\mathbf{9 6 4})$ & $\boldsymbol{P}$ value \\
\hline Time to extubation (h) & $8.1(6.0-12.3)$ & $10.5(7.0-17.0)$ & $<.001$ \\
ICU stay (h) & $47.5(43.0-50.5)$ & $49.5(44.5-86.4)$ & $<.001$ \\
Hospital stay (d) & $8.0(7.0-9.0)$ & $9.0(7.0-12.0)$ & $<.001$ \\
AKI stage by KDIGO & & & $<.001$ \\
$\quad$ KDIGO 0 & $1407(100 \%)$ & & \\
$\quad$ KDIGO 1 & & $723(75.0 \%)$ & \\
$\quad$ KDIGO 2 & $127(13.2 \%)$ & \\
$\quad$ KDIGO 3 & & $114(11.8 \%)$ & \\
In-hospital death & $3(0.2 \%)$ & $23(2.4 \%)$ & $<.001$ \\
1-y mortality & $11(0.8 \%)$ & $19(2.0 \%)$ & .011 \\
In-hospital RRT & $0(0 \%)$ & $62(6.4 \%)$ & $<.001$ \\
1-y RRT or death & $89(6.3 \%)$ & $204(21.2 \%)$ & $<.001$ \\
\hline
\end{tabular}

Data are expressed as the median (25th, 75th percentiles) or number (percentage) $A K I$, Acute kidney injury; ICU, intensive care unit; KDIGO, Kidney Disease: Improving Global Outcomes Definition and Staging; $R R T$, renal replacement therapy (1-year RRT or death, cases of RRT, or the number of deaths that occurred during the first postoperative year). 
TABLE 3. Multivariable logistic analysis for acute kidney injury in study patients who underwent elective coronary artery bypass grafting after coronary angiography

\begin{tabular}{|c|c|c|c|c|c|c|}
\hline & Odds ratio $(95 \% \mathrm{CI})$ & $P$ value & Odds ratio $(95 \% \mathrm{CI})$ & $P$ value & Odds ratio $(95 \% \mathrm{CI})$ & $P$ value \\
\hline & \multicolumn{2}{|c|}{ CABG $(n=2371)$} & \multicolumn{2}{|c|}{ ONCAB $(n=701)$} & \multicolumn{2}{|c|}{ OPCAB $(n=1670)$} \\
\hline Age & $1.013(1.002-1.023)$ & .016 & & & $1.018(1.005-1.031)$ & .007 \\
\hline Hypertension & $1.335(1.107-1.609)$ & .002 & $1.495(1.060-2.180)$ & .022 & $1.285(1.023-1.613)$ & .031 \\
\hline $\mathrm{eGFR}<60 \mathrm{~mL} / \mathrm{min} / 1.73 \mathrm{~m}^{2}$ & $1.759(1.358-2.280)$ & $<.001$ & $1.951(1.144-3.328)$ & .014 & $1.668(1.230-2.261)$ & .001 \\
\hline Insulin & $1.367(1.097-1.704)$ & .005 & & & $1.507(1.190-1.909)$ & .001 \\
\hline Hematocrit & $0.960(0.939-0.981)$ & $<.001$ & & & $0.953(0.928-0.978)$ & $<.001$ \\
\hline Albumin & $0.374(0.291-0.479)$ & $<.001$ & $0.271(0.173-0.426)$ & $<.001$ & $0.443(0.329-0.596)$ & $<.001$ \\
\hline Uric acid & $1.149(1.079-1.222)$ & $<.001$ & $1.173(1.037-1.327)$ & .011 & $1.143(1.062-1.230)$ & $<.001$ \\
\hline Use of CPB & $3.099(1.782-5.392)$ & $<.001$ & & & & \\
\hline CAG interval* (CPB use) & $0.775(0.667-0.901)$ & .001 & $0.810(0.688-0.954)$ & .012 & & \\
\hline CAG interval ${ }^{*}$ (CPB nonuse) & $0.931(0.851-1.019)$ & .121 & & & $0.929(0.849-1.017)$ & .110 \\
\hline Interaction (CAG interval* use of $\mathrm{CPB}$ ) & & .040 & & & & \\
\hline CPB time & & & $1.007(1.003-1.011)$ & $<.001$ & & \\
\hline Transfused $\mathrm{pRBC} \dagger$ & & & $1.198(1.087-1.320)$ & .001 & & \\
\hline
\end{tabular}

$C I$, Confidence interval; $C A B G$, coronary artery bypass grafting; $O N C A B$, on-pump coronary artery bypass; $O P C A B$, off-pump coronary artery bypass; $e G F R$, estimated glomerular filtration rate; $C P B$, cardiopulmonary bypass; $C A G$, coronary angiography; $p R B C$, packed red blood cells. * Log-transformed. †During operation.

$95 \%$ CI, $1.010-1.403, P=.037$ in categoric variables) (Table E1). There was significant interaction between the timing of coronary angiography and the use of CPB for postoperative AKI $(P=.019)$. After adjusting by the multivariable analysis, the result was not changed (Table 3). In multivariable logistic analysis, early surgery after coronary angiography was significantly associated with an increased risk of postoperative AKI in patients who underwent ONCAB (OR, 0.810; 95\% CI, 0.688-0.954; $P=.012$ ). However, the interval between coronary angiography and operation was not significantly associated with an increased risk of AKI in patients who underwent OPCAB (OR, 0.929; 95\% CI, 0.849-1.017; $P=.110)$. Other risk factors for postoperative AKI in ONCAB and OPCAB cases are shown in Table 3. In secondary analyses performed using a 7-day interval cutoff, we found similar results (Table E4).
In regard to propensity score matching analysis, independent predictors of AKI development and their ORs in the adjusted logistic regression model are listed in Table 4. In the adjusted logistic regression propensity score model, coronary angiography within 7 days of ONCAB was a predictor of postoperative AKI (OR, 1.742; 95\% CI, $1.144-2.653 ; P=.010)$. According to the logistic regression propensity score model, the interval between coronary angiography and $\mathrm{OPCAB}$ was not associated with an increased risk of postoperative AKI (unadjusted $P=.241$ and adjusted $P=.250$ ).

\section{DISCUSSION}

The results of our present investigation indicate that the risk of $A K I$ after $C A B G$ was influenced by the time interval between the coronary angiography and the operation.

TABLE 4. Adjusted odds ratio and $95 \%$ confidence intervals using a propensity score for acute kidney injury in study patients after coronary artery bypass grafting

\begin{tabular}{|c|c|c|c|c|c|c|}
\hline & \multicolumn{2}{|c|}{ Adjusted for propensity score $\nmid$} & \multicolumn{2}{|c|}{ Adjusted for propensity score $\dagger, \S$} & \multicolumn{2}{|c|}{ Adjusted for propensity score,$+ \|$} \\
\hline & Odds ratio $(95 \%$ CI) & $P$ value & Odds ratio $(95 \% \mathrm{CI})$ & $P$ value & Odds ratio $(95 \% \mathrm{CI})$ & $P$ value \\
\hline & \multicolumn{2}{|l|}{ CABG } & \multicolumn{2}{|l|}{ ONCAB } & \multicolumn{2}{|l|}{ OPCAB } \\
\hline Renal dysfunction & $3.143(2.014-4.905)$ & $<.001$ & $6.033(2.338-15.572)$ & $<.001$ & $2.309(1.464-3.642)$ & $<.001$ \\
\hline CAG interval $\leq 7 \mathrm{~d}$ & $1.224(0.999-1.499)$ & .051 & $1.742(1.144-2.653)$ & .010 & $1.147(0.910-1.450)$ & .250 \\
\hline Anesthetic time & & & $1.010(1.004-1.015)$ & $<.001$ & & \\
\hline Infused crystalloid* & $0.999(0.999-1.000)$ & $<.001$ & & & $0.999(0.999-1.000)$ & $<.001$ \\
\hline Infused colloid* & & & $0.998(0.997-0.999)$ & $<.001$ & & \\
\hline Transfused pRBC* & $1.294(1.177-1.423)$ & $<.001$ & $1.275(1.065-1.527)$ & .008 & $1.154(1.028-1.296)$ & .015 \\
\hline
\end{tabular}

$C I$, Confidence interval; $C A B G$, coronary artery bypass grafting; $O N C A B$, on-pump coronary artery bypass; $O P C A B$, off-pump coronary artery bypass; $C A G$, coronary angiography; $p R B C$, packed red blood cells. *During operation. †Propensity score developed for the likelihood of receiving CAG interval $\leq 7$ days. $\ddagger$ Hosmer-Lemeshow goodness-of-fit test $P=.467, \mathrm{C}$-stat $=0.635$. $\S$ Hosmer-Lemeshow goodness-of-fit test $P=.096, \mathrm{C}$-stat $=0.639 . \|$ Hosmer-Lemeshow goodness-of-fit test $P=.390, \mathrm{C}$-stat $=0.643$. 
However, the type of CABG-whether CPB was used or not-had different effects on the development of postoperative AKI. The occurrence of postoperative AKI in patients who underwent OPCAB was not affected by the time interval between the coronary angiography and the operation. To the best of our knowledge, our current report is the first to show that the effect of coronary angiography timing on AKI after CABG is influenced by the use of CPB.

Consistent with the findings of our present study, a number of previous studies reported that a short interval between coronary angiography and cardiac surgery could increase the risk of postoperative AKI., ${ }^{2,18-22}$ Although a short time between coronary angiography and cardiac surgery has been associated with increased risk of postprocedural AKI in some reports, most of these studies involved patients who underwent ONCAB or OPCAB concomitant with valve or aorta surgery using CPB. ${ }^{18,20-22}$ In contrast, we investigated how the relationship between the timing of the coronary angiography and the use of CPB affected renal function in a large group of patients who underwent elective CABG and adjusted the influence of potential confounding factors using multivariable logistic and propensity analyses.

Another important finding of our present study was that there was significant interaction between the timing of coronary angiography and the use of $\mathrm{CPB}$ in relation to postoperative AKI. The timing of coronary angiography did not affect the development of AKI in patients who underwent OPCAB. Our multivariable logistic and adjusted propensity score analyses showed that the interval between coronary angiography and subsequent OP$\mathrm{CAB}$ was not an independent predictor of the development of postoperative AKI, in contrast with ON$\mathrm{CAB}$. Our previous study also found that the risk of postoperative AKI was not related to the time between coronary angiography and $\mathrm{OPCAB} .{ }^{9}$ By avoiding the use of $\mathrm{CPB}$, OPCAB is expected to have a more beneficial effect on renal function than ONCAB in terms of AKI risk reduction. ${ }^{\text {? }}$

In contrast to our current findings, some previous studies have reported that a short interval between diagnostic coronary angiography and OPCAB is associated with an increased risk of postoperative AKI. ${ }^{23-25}$ One of these studies included a relatively small number of patients, ${ }^{24}$ and the report of $\mathrm{Ji}$ and colleagues ${ }^{25}$ excluded a time interval from coronary angiography until subsequent surgery of less than 24 hours. Zhang and colleagues ${ }^{26}$ also reported that one of the independent risk factors for postoperative AKI was OPCAB that was performed 24 hours or less after coronary angiography. However, they included patients who only underwent OPCAB after coronary angiography during the same hospitalization and had an interval between OPCAB and coronary angiography of 30 days or less, and they created only 4 subgroups according to the interval between coronary angiography and OPCAB $(\leq 24,24-48,48-72$, and $>72$ hours $) .{ }^{26}$ All of these differences in the study design might have influenced their results.

Our present study revealed that a shorter interval between coronary angiography and $\mathrm{CABG}$ influenced the occurrence of $\mathrm{AKI}$ in patients undergoing ONCAB. It is unclear why postoperative AKI is associated with a short interval between coronary angiography and ONCAB. However, some reports have hypothesized that AKI is related to a "double hit" on renal function. ${ }^{2,18,22}$ Contrast agents used for coronary angiography before cardiac surgery could induce renal damage, such as contraction of renal blood vessels and ischemia-mediated oxidative stress, and cytotoxic effects are independently associated with increased postoperative AKI. ${ }^{3,19}$ Several studies have reported that postoperative AKI is a consequence of interplay among different pathophysiologic mechanisms, with patient-related factors and CPB being major causes. $^{4,27}$ These factors include concomitant valve surgery with CABG; the bypass procedure itself, such as the crossclamp time, duration of $\mathrm{CPB}$, severe hemodilution (as reflected by nadir hematocrit), and low oxygen delivery during $\mathrm{CPB}$; and low cardiac output syndrome in the postoperative course. ${ }^{3,7,28}$ In agreement with previous results showing that the use of CPB worsened renal function, , $3,6,7,27-29_{\text {our present findings }}$ have revealed a higher incidence of postoperative AKI in patients who underwent ONCAB than in those who underwent $\mathrm{OPCAB}$.

Indications for OPCAB surgery vary widely. In general, patients who were elderly with 2 or more comorbidities, such as calcified aorta, recent stroke, severe carotid disease, and renal dysfunction, were preferentially approached by an off-pump technique, given that their anatomy allowed this approach to be effective and safe. ${ }^{30,31}$ In our study, the patients undergoing OPCAB were more current smokers and had a higher incidence of hypertension and peripheral vascular disease. Otherwise, the patients undergoing OPCAB had a lower logistic European System for Cardiac Operative Risk Evaluation than those undergoing ONCAB. The low-risk patients might be selected for OPCAB in some centers. It is clear that the greatest benefit of OPCAB surgery may be in patients with the highest risk and in elderly patients. In contrast to prospective randomized trials of nonselected patients, this study intentionally selected patients on the basis of anatomy and patient comorbid conditions for the off-pump group because we aimed at maximal incremental risk reduction for all patients and the greatest therapeutic margin. ${ }^{31}$ However, it would be another unexpected bias. Thus, we cannot completely 
exclude the possibility that this unknown bias may have influenced our results.

The incidence of postoperative AKI in our patient cohort is higher than reported by previous studies on the incidence of AKI after OPCAB or on-pump cardiac surgery according to the Risk, Injury, Failure, Loss, and End-stage kidney disease criteria or AKI Network criteria. ${ }^{1-3}$ A wide disparity between our cohort and other studies may be due to the use of the KDIGO definition of AKI and differences of management strategies in the pericatheterization period or perioperative care protocol, such as the use of inotropes, vasoactive agents, and fluid administration. In our institution, use of $6 \%$ hydroxyethyl starch 130/0.4 was generally available. Our strategy of fluid management restricted crystalloid use, and the crystalloid/ colloid volume ratio was lower than reported in other studies, ${ }^{24}$ especially in the AKI group. Several recent studies demonstrated that intraoperative hydroxyethyl starch administration was associated with the occurrence of postoperative AKI. ${ }^{32,33}$ The use of hydroxyethyl starch would have influenced the increasing incidence of postoperative AKI. We are continually working on reducing the occurrence of postoperative AKI, and further studies are needed.

On the basis of its results, our present study may have clinical significance. Our study revealed that a shorter interval between coronary angiography and CABG had a serious effect on the occurrence of AKI in patients undergoing ONCAB only. The timing of coronary angiography did not affect the development of postoperative AKI in patients who underwent OPCAB. Our current evidence should be considered when seeking greater convenience for patients, reducing the economic burden, and reducing the hospital stay. ${ }^{34,35}$ However, this hypothesis requires a further large prospective, randomized, controlled study to be confirmed.

\section{Study Limitations}

First, this was a retrospective single-center observational study with inherent limitations and possible selection biases. Because of the observational nature of this study, our findings should be regarded as hypothesis generating. Thus, we attempted to adjust for variables collected in our database by assessing the impact of the interval between coronary angiography and CABG on postoperative AKI while using stratification on the propensity score. Second, we did not verify if the contrast agents induced renal damage before surgery, although preexisting kidney injury was accepted as an important risk factor for AKI. However, in our previous study, we found that ionic contrast agents or a high dose of intravenous contrast agent was not a predictor of postoperative AKI. ${ }^{9}$ Finally, we were unable to identify the pathologic mechanisms accounting for the different effects of $\mathrm{CPB}$ and the interval between coronary angiography and CABG on postoperative AKI. Thus, further analysis is needed to elucidate this unknown mechanism.

\section{CONCLUSIONS}

A shorter interval between coronary angiography and CABG influenced the occurrence of AKI in patients undergoing ONCAB. However, the interval is not an independent risk factor for the development of postoperative $\mathrm{AKI}$ in patients who undergo OPCAB.

\section{Conflict of Interest Statement}

Authors have nothing to disclose with regard to commercial support.

\section{References}

1. Ostermann ME, Taube D, Morgan CJ, Evans TW. Acute renal failure following cardiopulmonary bypass: a changing picture. Intensive Care Med. 2000;26: $565-71$.

2. Medalion B, Cohen H, Assali A, Vaknin Assa H, Farkash A, Snir E, et al. The effect of cardiac angiography timing, contrast media dose, and preoperative renal function on acute renal failure after coronary artery bypass grafting. $J$ Thorac Cardiovasc Surg. 2010;139:1539-44.

3. Mariscalco G, Lorusso R, Dominici C, Renzulli A, Sala A. Acute kidney injury: a relevant complication after cardiac surgery. Ann Thorac Surg. 2011;92:1539-47.

4. Rosner MH, Portilla D, Okusa MD. Cardiac surgery as a cause of acute kidney injury: pathogenesis and potential therapies. I Intensive Care Med. 2008;23:3-18.

5. Conlon PJ, Stafford-Smith M, White WD, Newman MF, King S, Winn MP, et al. Acute renal failure following cardiac surgery. Nephrol Dial Transplant. 1999;14: 1158-62.

6. Aronson S, Fontes ML, Miao Y, Mangano DT. Risk index for perioperative renal dysfunction/failure: critical dependence on pulse pressure hypertension. Circulation. 2007; 115:733-42.

7. Brown JR, Cochran RP, Leavitt BJ, Dacey LJ, Ross CS, MacKenzie TA, et al. Multivariable prediction of renal insufficiency developing after cardiac surgery Circulation. 2007;116:I139-43.

8. Mehta RH, Honeycutt E, Patel UD, Lopes RD, Williams JB, Shaw LK, et al. Relationship of the time interval between cardiac catheterization and elective coronary artery bypass surgery with postprocedural acute kidney injury. Circulation. 2011;124:S149-55.

9. Lee EH, Chin JH, Joung KW, Choi DK, Kim WJ, Lee JB, et al. Impact of the time of coronary angiography on acute kidney injury after elective off-pump coronary artery bypass surgery. Ann Thorac Surg. 2013;96:1635-41.

10. Schopka S, Diez C, Camboni D, Floerchinger B, Schmid C, Hilker M. Impact of cardiopulmonary bypass on acute kidney injury following coronary artery bypass grafting: a matched pair analysis. J Cardiothorac Surg. 2014;9:20.

11. Shroyer AL, Grover FL, Hattler B, Collins JF, McDonald GO, Kozora E, et al. On-pump versus off-pump coronary-artery bypass surgery. $N$ Engl $\mathrm{J} \mathrm{Med}$. 2009;361:1827-37.

12. Levey AS, Bosch JP, Lewis JB, Greene T, Rogers N, Roth D. A more accurate method to estimate glomerular filtration rate from serum creatinine: a new prediction equation. Modification of Diet in Renal Disease Study Group. Ann Intern Med. 1999;130:461-70.

13. von Elm E, Altman DG, Egger M, Pocock SJ, Gotzsche PC, Vandenbroucke JP. The Strengthening the Reporting of Observational Studies in Epidemiology (STROBE) statement: guidelines for reporting observational studies. Lancet. 2007;370:1453-7.

14. Lee EH, Yun SC, Chin JH, Choi DK, Son HJ, Kim WC, et al. Prognostic implications of preoperative $\mathrm{E} / \mathrm{e}^{\prime}$ ratio in patients with off-pump coronary artery surgery. Anesthesiology. 2012;116:362-71.

15. Kellum JA, Lameire N. Diagnosis, evaluation, and management of acute kidney injury: a KDIGO summary (Part 1). Crit Care. 2013;17:204.

16. McCullough PA. Contrast-induced acute kidney injury. J Am Coll Cardiol. 2008; 51:1419-28. 
17. Mehran R, Nikolsky E. Contrast-induced nephropathy: definition, epidemiology, and patients at risk. Kidney Int Suppl. 2006;S11-5.

18. Del Duca D, Iqbal S, Rahme E, Goldberg P, de Varennes B. Renal failure after cardiac surgery: timing of cardiac catheterization and other perioperative risk factors. Ann Thorac Surg. 2007;84:1264-71.

19. Ranucci M, Ballotta A, Kunkl A, De Benedetti D, Kandil H, Conti D, et al, Influence of the timing of cardiac catheterization and the amount of contrast media on acute renal failure after cardiac surgery. Am J Cardiol. 2008;101: 1112-8.

20. Mariscalco G, Cottini M, Dominici C, Banach M, Piffaretti G, Borsani P, et al. The effect of timing of cardiac catheterization on acute kidney injury after cardiac surgery is influenced by the type of operation. Int J Cardiol. 2014;173: 46-54.

21. Hu Y, Li Z, Chen J, Shen C, Song Y, Zhong Q. Risk factors for acute kidney injury in patients undergoing same admission coronary angiography and valve replacement. J Card Surg. 2013;28:627-31.

22. Ranucci M, Ballotta A, Agnelli B, Frigiola A, Menicanti L, Castelvecchio S. Acute kidney injury in patients undergoing cardiac surgery and coronary angiography on the same day. Ann Thorac Surg. 2013;95:513-9.

23. Kim MY, Jang HR, Huh W, Kim YG, Kim DJ, Lee YT, et al. Incidence, risk factors, and prediction of acute kidney injury after off-pump coronary artery bypass grafting. Ren Fail. 2011;33:316-22.

24. Kim NY, Kim SY, Lee NH, Kwak YL. Impact of the interval between coronary angiography and off-pump coronary bypass surgery on postoperative renal function. Korean J Anesthesiol. 2010;58:142-7.

25. Ji Q, Mei Y, Wang X, Feng J, Wusha D, Cai J, et al. Effect of elapsed time from coronary angiography until off-pump coronary artery bypass surgery on postoperative renal function. Circ J. 2012;76:2356-62.

26. Zhang Y, Ye N, Chen YP, Cheng H. Relation between the interval from coronary angiography to selective off-pump coronary artery bypass grafting and postoperative acute kidney injury. Am J Cardiol. 2013;112:1571-5.

27. von Heymann C, Sander M, Foer A, Heinemann A, Spiess B, Braun J, et al. The impact of an hematocrit of $20 \%$ during normothermic cardiopulmonary bypass for elective low risk coronary artery bypass graft surgery on oxygen delivery and clinical outcome-a randomized controlled study [ISRCTN35655335]. Crit Care. 2006;10:R58.

28. Massoudy P, Wagner S, Thielmann M, Herold U, KottenbergAssenmacher E, Marggraf G, et al. Coronary artery bypass surgery and acute kidney injury-impact of the off-pump technique. Nephrol Dial Transplant. 2008:23:2853-60.

29. Rosner MH, Okusa MD. Acute kidney injury associated with cardiac surgery. Clin J Am Soc Nephrol. 2006;1:19-32.

30. Hirose H. Current trend of off-pump coronary artery bypass grafting. In: Nazari S, ed. Front Lines of Thoracic Surgery. Rijeka, Croatia: InTech; 2012: 47-60.

31. Brown JM, Poston RS, Gammie JS, Cardarelli MG, Schwartz K, Sikora JA, et al Off-pump versus on-pump coronary artery bypass grafting in consecutive patients: decision-making algorithm and outcomes. Ann Thorac Surg. 2006;81: 555-61.

32. Ahn HJ, Kim JA, Lee AR, Yang M, Jung HJ, Heo B. The risk of acute kidney injury from fluid restriction and hydroxyethyl starch in thoracic surgery. Anesth Analg. 2016;122:186-93.

33. Hand WR, Whiteley JR, Epperson TI, Tam L, Crego H, Wolf B, et al Hydroxyethyl starch and acute kidney injury in orthotopic liver transplantation: a single-center retrospective review. Anesth Analg. 2015;120: 619-26.

34. Kramer RS, Quinn RD, Groom RC, Braxton JH, Malenka DJ, Kellett MA, et al Same admission cardiac catheterization and cardiac surgery: is there an increased incidence of acute kidney injury? Ann Thorac Surg. 2010;90:1418-24.

35. Brown ML, Holmes DR, Tajik AJ, Sarano ME, Schaff HV. Safety of same-day coronary angiography in patients undergoing elective valvular heart surgery. Mavo Clin Proc. 2007:82:572-4.

Key Words: acute kidney injury, cardiopulmonary bypass, coronary angiography, coronary artery bypass grafting, offpump coronary artery bypass grafting 


\section{SUPPLEMENTAL METHODS}

To control the selection bias related to covariates, a propensity score for the likelihood of receiving coronary angiography 7 days or less before CABG was developed, and a hierarchic logistic regression model to calculate the propensity score was applied. In this case, the propensity score represented the estimated probability of receiving coronary angiography 7 days or less before CABG (vs $>7$ days) as a function of the patient's baseline and comorbidities, as well as preoperative cardiac medications, age, gender, body mass index, diabetes, hypertension, smoking, congestive heart failure, cerebrovascular disease, peripheral vascular disease, preoperative liver disease, preoperative angiotensin-converting enzyme inhibitors, beta-blockers, calcium channel blockers, insulin, oral hypoglycemic agents, statins, aspirin, clopidogrel, diuretics, preoperative hematocrit, creatinine, total bilirubin, albumin, uric acid, and preoperative left ventricular ejection fraction (c statistic 0.635 ). The propensity score was based on the following variables: preoperative renal dysfunction, coronary angiography within 7 days before surgery, use of
$\mathrm{CPB}$, anesthetic time, infused fluid in the operating room, and transfused blood components in the operating room. This process generated a propensity score between 0 and 1 , and patients who received coronary angiography 7 days or less before the CABG were matched 1:1 to patients who received coronary angiography more than 7 days before the CABG. After the propensity score match was performed, we assessed the differences between the 2 groups. Absolute standardized differences were estimated to evaluate the prematch imbalance and postmatch balance. An absolute standardized difference of $0 \%$ indicated no residual bias, and differences less than $15 \%$ were considered inconsequential.

\section{E-Reference}

E1. Vincent JL, de Mendonca A, Cantraine F, Moreno R, Takala J, Suter PM, et al. Use of the SOFA score to assess the incidence of organ dysfunction/failure in intensive care units: results of a multicenter, prospective study. Working group on "sepsis-related problems" of the European Society of Intensive Care Medicine. Crit Care Med. 1998;26:1793-800. 
TABLE E1. Univariate logistic analyses

\begin{tabular}{|c|c|c|c|c|c|c|}
\hline & Odds ratio $(95 \%$ CI $)$ & $P$ value & Odds ratio $(95 \%$ CI $)$ & $P$ value & Odds ratio $(95 \% \mathrm{CI})$ & $P$ value \\
\hline & \multicolumn{2}{|c|}{$\operatorname{CABG}(n=2371)$} & \multicolumn{2}{|c|}{ ONCAB $(n=701)$} & \multicolumn{2}{|c|}{ OРCAB $(n=1670)$} \\
\hline Age & $1.029(1.019-1.038)$ & $<.001$ & $1.014(0.997-1.031)$ & .097 & $1.037(1.025-1.049)$ & $<.001$ \\
\hline Gender & $1.057(0.873-1.280)$ & .568 & $0.914(0.654-1.227)$ & .597 & $1.100(0.870-1.391)$ & .427 \\
\hline Body mass index & $0.995(0.967-1.023)$ & .709 & $0.991(0.943-1.043)$ & .736 & $0.996(0.962-1.031)$ & .809 \\
\hline Hypertension & $1.534(1.291-1.823)$ & $<.001$ & $1.605(1.184-2.174)$ & .002 & $1.573(1.272-1.947)$ & $<.001$ \\
\hline Diabetes mellitus & $1.448(1.228-1.707)$ & $<.001$ & $1.166(0.866-1.570)$ & .311 & $1.614(1.321-1.972)$ & $<.001$ \\
\hline \multicolumn{7}{|l|}{ Smoking } \\
\hline Nonsmoker & 1 & & 1 & & 1 & \\
\hline Ex-smoker & $1.074(0.886-1.302)$ & .468 & $1.215(0.870-1.698)$ & .253 & $0.997(0.786-1.265)$ & .981 \\
\hline Smoker & $0.948(0.771-1.165)$ & 609 & $1.053(0.703-1.578)$ & .802 & $0.965(0757-1.231)$ & .775 \\
\hline $\mathrm{CHF}$ & $2.055(1.293-3.265)$ & .002 & $2.814(1.289-6.145)$ & .009 & $1.508(0.821-2.769)$ & .185 \\
\hline CVD & $1.542(1.278-1.861)$ & $<.001$ & $1.451(1.059-1.988)$ & .021 & $1.442(1.135-1.833)$ & .003 \\
\hline PVD & $1.257(0.874-1.807$ & .217 & $1.643(0.735-3.673)$ & .226 & $1.251(0.826-1.893)$ & .29 \\
\hline $\mathrm{eGFR}<60 \mathrm{~mL} / \mathrm{min} / 1.73 \mathrm{~m}^{2}$ & $3.156(2.526-3.944)$ & $<.001$ & $3.460(2.250-5.321)$ & $<.001$ & $3.082(2.367-4.014)$ & $<.001$ \\
\hline Liver disease & $1.383(0.841-2.275)$ & .201 & $1.268(0.495-3.253)$ & .621 & $1.457(0.808-2.625)$ & .211 \\
\hline ACEi & $1.415(1.199-1.670)$ & $<.001$ & $1.294(0.961-1.744)$ & .09 & $1.449(1.185-1.773)$ & $<.001$ \\
\hline Beta-blocker & $1.028(0.868-1.217)$ & .750 & $0.897(0.665-1.211)$ & .479 & $1.156(0.938-1.424)$ & .174 \\
\hline $\mathrm{CCB}$ & $0.901(0.754-1.076)$ & .249 & $0.689(0.506-0.939)$ & .018 & $1.107(0.885-1.384)$ & .373 \\
\hline Insulin & $1.431(1.176-1.741)$ & $<.001$ & $1.124(0.665-1.902)$ & .662 & $1.787(1.435-2.224)$ & $<.001$ \\
\hline OHA & $1.259(1.062-1.491)$ & .008 & $1.158(0.854-1.569)$ & .346 & $1.288(1.048-1.583)$ & .16 \\
\hline Statin & $0.796(0.666-0.950)$ & .012 & $0.619(0.451-0.850)$ & .003 & $0.922(0.741-1.147)$ & .467 \\
\hline Aspirin & $1.112(0.919-1.344)$ & .275 & $1.182(0.800-1.746)$ & .4 & $1.002(0.804-1.250)$ & .983 \\
\hline Clopidogrel & $0.982(0.833-1.159)$ & .833 & $1.050(0.771-1.431)$ & .756 & $0.880(0.721-1.074)$ & .208 \\
\hline Diuretics & $1.206(0.980-1.483)$ & .077 & $1.096(0.771-1.559)$ & .61 & $1.198(0.924-1.552)$ & .172 \\
\hline Logistic euroSCORE & $1.091(1.068-1.115)$ & $<.001$ & $1.058(1.030-1.087)$ & $<.001$ & $1.110(1.073-1.148)$ & $<.001$ \\
\hline Hematocrit & $0.905(0.889-0.921)$ & $<.001$ & $0.918(0.889-0.948)$ & $<.001$ & $0.899(0.880-0.919)$ & $<.001$ \\
\hline Creatinine & $2.510(1.975-3.191)$ & $<.001$ & $2.798(1.720-4.552)$ & $<.001$ & $2.448(1.860-3.222)$ & $<.001$ \\
\hline Total bilirubin & $0.650(0.480-0.881)$ & .005 & $1.021(0.584-1.785)$ & .943 & $0.524(0.359-0.763)$ & .001 \\
\hline Albumin & $0.252(0.203-0.313)$ & $<.001$ & $0.206(0.138-0.307)$ & $<.001$ & $0.290(0.224-0.377)$ & $<.001$ \\
\hline Uric acid & $1.156(1.095-1.220)$ & $<.001$ & $1.211(1.096-1.338)$ & $<.001$ & $1.140(1.068-1.217)$ & $<.001$ \\
\hline Ejection fraction & $0.984(0.977-0.992)$ & $<.001$ & $0.977(0.996-0.989)$ & $<.001$ & $0.993(0.984-1.003)$ & .168 \\
\hline CAG interval (log transformed) & $0.921(0.858-0.989)$ & .023 & $0.791(0.688-0.910)$ & .001 & $0.961(0.884-1.046)$ & .358 \\
\hline CPB use & $1.701(1.423-2.033)$ & $<.001$ & & & & \\
\hline Interaction (CAG interval* $\mathrm{CPB}$ use) & & .019 & & & & \\
\hline Anesthetic time & $1.001(1.000-1.002)$ & .152 & $1.004(1.002-1.006)$ & $<.001$ & $0.999(0.997-1.000)$ & .163 \\
\hline CPB time & & & $1.009(1.005-1.013)$ & $<.001$ & & \\
\hline Anastomosed vessels, $\mathrm{n}$ & $0.952(0.874-1.036)$ & .251 & $1.140(0.972-1.338)$ & .108 & $0.897(0.810-0.993)$ & .036 \\
\hline $\mathrm{RBC}^{*}$ & $1.877(1.586-2.221)$ & $<.001$ & $2.342(1.699-3.2229)$ & $<.001$ & $1.602(1.310-1.958)$ & $<.001$ \\
\hline FFP* & $1.733(1.264-2.376)$ & .001 & $2.273(1.428-3.620)$ & .001 & $1.001(0.621-1.612)$ & .998 \\
\hline Cell salvage blood* & $0.731(0.612-0.873)$ & .001 & $0.787(0.482-1.286)$ & .339 & $0.854(0.697-1.046)$ & .127 \\
\hline Crystalloid* & $1.000(0.999-1.000)$ & $<.001$ & $1.000(1.000-1.000)$ & .773 & $1.000(0.999-1.000)$ & $<.001$ \\
\hline Colloid* & $1.000(0.999-1.000)$ & $<.001$ & $1.000(0.999-1.000)$ & .488 & $1.000(0.999-1.000)$ & .013 \\
\hline
\end{tabular}

$C I$, Confidence interval; $C A B G$, coronary artery bypass grafting; $O N C A B$, on-pump coronary artery bypass; $O P C A B$, off-pump coronary artery bypass; $C H F$, congestive heart failure; $C V D$, cerebrovascular disease; $P V D$, peripheral vascular disease; $e G F R$, estimated glomerular filtration rate; $A C E i$, angiotensin-converting enzyme inhibitor; $C C B$, calcium channel blocker; OHA, oral hypoglycemic agent; euroSCORE, European System for Cardiac Operative Risk Evaluation; CAG, coronary angiography; $C P B$, cardiopulmonary bypass; $p R B C$, packed red blood cell; $F F P$, fresh-frozen plasma. *Admitted during operation. 
TABLE E2. Morbidity in the study cohort with reference to acute kidney injury development

\begin{tabular}{lccr}
\hline & No AKI $(\mathbf{n}=\mathbf{1 4 0 7})$ & AKI $(\mathbf{n}=\mathbf{9 6 4})$ & $\boldsymbol{P}$ value \\
\hline Reoperation & $19(1.4 \%)$ & $29(3.0 \%)$ & .007 \\
CV-SOFA score & $2.2 \pm 1.2$ & $2.5 \pm 1.2$ & $<.001$ \\
Weight change $(\mathrm{kg})$ & $1.0 \pm 1.3$ & $1.3 \pm 1.4$ & $<.001$ \\
\hline
\end{tabular}

Data are expressed as the mean \pm standard deviation (median) or number (percentage). AKI, Acute kidney injury; CV-SOFA, Cardiovascular Sequential Organ Failure Assessment (score during the first 24 hours of ICU stay ${ }^{\mathrm{E} 1}$ ).

TABLE E3. Mortality and morbidity in the study cohort with reference to mild acute kidney injury (Kidney Disease: Improving Global Outcomes Definition and Staging 1) development

\begin{tabular}{lccr}
\hline & $\begin{array}{c}\text { No AKI } \\
(\mathbf{n}=\mathbf{1 4 0 7})\end{array}$ & $\begin{array}{c}\text { KDIGO 1 } \\
(\mathbf{n = 7 2 3})\end{array}$ & $\begin{array}{c}\boldsymbol{P} \\
\text { value }\end{array}$ \\
\hline Time to extubation (h) & $8.1(6.0-12.3)$ & $10.0(7.0-16.0)$ & $<.001$ \\
ICU stay (h) & $47.5(43.0-50.5)$ & $49.0(43.5-72.0)$ & $<.001$ \\
Hospital stay (d) & $8.0(7.0-9.0)$ & $8.0(7.0-10.0)$ & $<.001$ \\
In-hospital death & $3(0.2 \%)$ & $5(0.7 \%)$ & .130 \\
1-y mortality & $11(0.8 \%)$ & $12(1.7 \%)$ & .076 \\
\hline
\end{tabular}

Data are expressed as the median (25th, 75th percentiles) or number (percentage).

$A K I$, Acute kidney injury; KDIGO, Kidney Disease: Improving Global Outcomes

Definition and Staging; $I C U$, intensive care unit.

TABLE E4. Relationship between coronary artery bypass grafting performed 7 days or less after coronary angiography and acute kidney injury

\begin{tabular}{|c|c|c|c|c|c|c|}
\hline \multirow[b]{3}{*}{ Age } & Odds ratio $(95 \% \mathrm{CI})$ & $\boldsymbol{P}$ & Odds ratio $(95 \% \mathrm{CI})$ & $\boldsymbol{P}$ & Odds ratio $(95 \% \mathrm{CI})$ & $\boldsymbol{P}$ \\
\hline & \multicolumn{2}{|c|}{ CABG $(n=2371)$} & \multicolumn{2}{|c|}{ ONCAB $(n=701)$} & \multicolumn{2}{|c|}{ OPCAB $(n=1670)$} \\
\hline & $1.013(1.002-1.023)$ & .015 & & & $1.018(1.005-1.031)$ & .007 \\
\hline Hypertension & $1.341(1.112-1.616)$ & .002 & $1.543(1.096-2.172)$ & .013 & $1.285(1.023-1.613)$ & .031 \\
\hline $\mathrm{eGFR}<60 \mathrm{~mL} / \mathrm{min} / 1.73 \mathrm{~m}^{2}$ & $1.748(1.349-2.266)$ & $<.001$ & $1.972(1.164-3.341)$ & .012 & $1.668(1.230-2.261)$ & .001 \\
\hline Insulin & $1.364(1.094-1.699)$ & .006 & & & $1.507(1.190-1.909)$ & .001 \\
\hline Hematocrit & $0.961(0.940-0.981)$ & $<.001$ & & & $0.953(0.928-0.978)$ & $<.001$ \\
\hline Albumin & $0.372(0.290-0.477)$ & $<.001$ & $0.246(0.158-0.383)$ & $<.001$ & $0.443(0.329-0.596)$ & $<.001$ \\
\hline Uric acid & $1.149(1.080-1.222)$ & $<.001$ & $1.173(1.037-1.327)$ & .011 & $1.142(1.061-1.230)$ & $<.001$ \\
\hline Use of CPB & $1.517(1.153-1.995)$ & .003 & & & & \\
\hline CAG interval* (CPB use) & $1.609(1.170-2.211)$ & .003 & $1.503(1.073-2.106)$ & .018 & & \\
\hline CAG interval* (CPB nonuse) & $1.154(0.932-1.428)$ & .188 & & & $1.161(0.938-1.437)$ & .171 \\
\hline Interaction $\left(\mathrm{CAG} \leq 7 \mathrm{~d}^{*}\right.$ use of $\left.\mathrm{CPB}\right)$ & & .029 & & & & \\
\hline CPB time & & & $1.008(1.004-1.012)$ & $<.001$ & & \\
\hline Transfused $\mathrm{pRBC} \dagger$ & & & $1.664(1.158-2.392)$ & .006 & & \\
\hline
\end{tabular}

